\title{
Role of Urban Regeneration in Strengthening Community Development (Case Study: Kowsar neighborhood, Region 12 (Tehran))
}

\author{
Malihe Ahmadi \\ Department of Urbanization, Shahr-e-Qods Branch, Islamic Azad University, Tehran, Iran
}

\author{
Doi:10.5901/mjss.2016.v7n3s3p43
}

\section{Abstract}

The development of social and physical aspects of cities resulted from urban population growth has had a considerable and inevitable impact on city life. The impacts include a wide range of social, economic, cultural, and physical deficiencies. Moreover, the mentioned aspects have mutual relations with one another. What really matters is the quantitative and qualitative human relationships. The warm and friendly human relationships in the urban communities have diminished and human relationships are defined in the forms of formal and work relations. This is the origin of many of the social-mental problems and it has manifested in the metropolises. Face to face interactions, sense of belonging, social relations, and so forth are the specifications of the neighborhoods. Some of the mentioned specifications are used to define the communities. However, the urbanism has failed to solve urban problems, because it has a merely physical approach to development and it ignores social and cultural problems. The world experiences as well as the domestic experiences of urbanism prove that a top-down view in the form of different maps of application, density, and so forth have failed to address the problems. The present paper intends to study Kowsar neighborhood that is one of the neighborhoods located in region 12 of Tehran municipality between Khorasan street and North Shush street. It is one of the old neighborhoods of Tehran and it had a special place in the past periods. There were high social interactions in the mentioned place, however, its social interactions decreased as a result of the entrance of residents of others cities (especially the workers) into this area, its being close to Tehran Bazaar, property wear, the change of residential units into production units, and its marginalization over time. The present paper applies analytical-descriptive method as well as Spearman's correlation coefficient in order to express its findings and representing the best strategies in order to increase the social interactions in Kowsar neighborhood.

Keyword: urban regeneration, strengthening community development, Kowsar neighborhood

\section{Introduction}

Over the recent decades, urbanism has confronted new challenges as a result of increasing growth of cities and the formation of different dimensions of urban problems. For some reasons, this issue has emerged in the big cities. The population growth and the development of physical dimensions in big cities have increased, moreover, providing more services and facilities in cities has led to more population and many problems. In order to reach a sustainable solution for the complex aspects of urban problems, it is needed to fully pay attention to different aspects of the problems (Papoli Yazdi, Mohammad Hosein; 2003, p.52).

The macro urban-scaled plans in the form of comprehensive urbanisms have failed to reach success as a result of paying attention to limited aspects of the urban life. Recently, urban planning and management has emphasized paying attention to the more tangible and lower classes of the urban life. Therefore, different research studies done over the last two decades have intended to determine policies, plans, and urban management for the smallest urban unit" neighborhood". The present paper intends to have a study on Kowsar neighborhood located in region 12 of Tehran regarding physical and environmental programs, as well as social and cultural programs in order to recreate the neighborhood. It is a neighborhood known with the historical and cultural identity, however, it is declining.

Statement of problem

Approximately half a century ago, the famous analyst Lewis Mumford supported the idea of urbanism. To him, wherever humans gather together the communities change into social realities. However, the sociologist, urban planners, and urban designers should seriously pay attention to urban small communities. In fact, communities are known as a means of efficient urban management, sustainable development, making distinctions, understanding the unknown issues, and promoting social solidarity. In fact, urban life has complicated aspects as the components of a system and they have mutual effects on one another. It is impossible to perceive the aspects by having a top down view, therefore, it is needed to concentrate on the micro analysis and a tangible scale. 
Therefore, the concept of community- based planning has been mentioned. It is planning based on social engineering and it concentrates on micro and local scale instead of macro and mental scales. In fact, this pattern attempts to recognize the abilities and specifications of urban areas and communities hidden or forgotten by the cityscaled conventional assumptions (Hajipour, Khalil, 2003; p.124).

The community based approach refers to the planning perspective and its management is based on down top view based on empowerment. It includes the need-based attitude and the asset-based attitude. According to the need-based attitude, the needs of any local community is the basis for its development. According to the asset-based attitude, human resources, quality and quantity of relations, and participation of the community residents in the form of social capitals are considered as tools and causes for community development. It should be mentioned that the concept of social capital entered the urban planning literature in the 60 s decade with the publication of the famous book titled as "the death and life of great American cities" written by Jane Jacobs.

Social capitals are considered as the hidden wealth of the society and regarding the concept of community, they can be more emerged in the community considering common interests, and face to face relations among residents. However, the managers of countries and urban managers have ignored it. It seems that it is facilitated to reach the hidden wealth (social capital) in order to reach community development and finally urban development (physical- socialeconomic dimensions) via considering the social and physical dimensions of community as an urban unit that makes the foundation of physical-social organization of the city (Dickens, Peter, 2009; p.65).

Recently, the managers of metropolises have paid attention to the community development approach as the basis for sustainable urban development. It is appropriate to study the ways for reaching community development as an aspect of micro-urbanism paradigm. Sari located in Mazandaran province has special features of tourism, therefore, it is influenced by the increasing growth of population and it confronts more severe problems (Sharifian Sani, 2001; p. 24).

Therefore, the present paper studies Kowsar neighborhood located in region 12, district 5 of Tehran. It intends to improve the neighborhood considering civil participation and local-social development in order to achieve its past socialdevelopmental identity.

\section{The Importance of Research}

Humans feel lonely as a result of development of modernity, globalization, and individualism. This is more obvious in the metropolises as a physical manifestation of modernity. Simmel says" in the metropolises and cities, the more bodies are pressed against each other, the more hearts get far from one another". There are many research studies associated with the effect of community on social interactions, economic capital, social solidarity, and finally economic and social sustainability. From the early research studies done by Simmel, Wirth, Rodfild, Gans, and Fisher to the contemporary theorists all are concerned with economic interactions. Today, social and economic relations within a community or subjects such as social and economic capital, political power, and even mental health are discussed (Khosravi Gharai and Taghavi, 2014). In the new era, the structure and function of city communities have totally changed. Moreover, population immigration and residents' staying in the neighborhoods, and also lack of necessary policies such as sustainable planning have increased environmental problems. The problems not only threaten the residents of the neighborhoods nut also the whole region as a result of existence of the communication among the communities of the cities and their social and economic interactions. Some of the current problems result from physical and economic underdevelopment of the urban neighborhoods (Fukuyama, Francis, 2008; p. 157).

Currently, economic and social distance and unequal distribution of general services and facilities in Kowsar neighborhood have changed it into a heterogeneous neighborhood regarding social, economic, and cultural issues. The heterogeneity has emerged in the whole community especially the south part of it. In many of the neighborhood units, durable settlement attractions have decreased and activities among neighborhoods have confronted many development obstacles. Urban neighborhoods (communities) have a basic role in the life and death of cities. The change of the relation between mas and space and the change in human and buildings density all resulted from change in life styles and the increase of urban population growth have led to basic changes in the spatial structure of communities and the economic, social interactions at the local level. The inevitable changes in communities and cities have caused many problems. According to the close relationship between spatial structure and social structure of the communities, it is needed to make changes in each of them in order to improve them. Providing the field for the people's participation in forming their working and living places could make the community and finally, the whole city have all the required features. The present paper assumes that it is possible to increase the social interactions of Kowsar neighborhood via appropriately designing a proper center for it. Therefore, it is necessary to pay attention to the development of neighborhoods and Kowsar neighborhood which are studied in the urban comprehensive plans. Therefore, the paper intends to determine 
planning policies for improving the quality of urban neighborhoods centers especially in Kowsar neighborhood located in region 12 of Tehran with regard to the quality concepts of the neighborhoods centers and emphasizing the social sustainability approach.

\section{Research Background}

According to the theoretical study, the effect of human-made community on economic interactions refers to the early modernism in urbanism. Arthur Perry has been the first person to discuss it. He designed neighborhood unit in order to design the neighborhood so that the economic interactions could be promoted. Later, Letchworth and Welwyn garden cities were designed based on his pattern. In England, Milton Keynes and Cumberland cities were designed and constructed based on economic motivations. The contemporary theory in England that discusses the mentioned issues refers to the urban regeneration. Unlikely, the suburbs put emphasis on individuals' personal life. The suburb fails to increase unpredicted social interactions. In order to confront these sorts of urban neighborhoods, new urbanism movement and smart growth attempt to regenerate local economic relations by following traditional neighborhood development (TND) design. Regeneration projects such as Seaside Florida have almost been successful in improving different aspects of economic sustainability.

Unfortunately, social-economic aspects of physical interventions are not emphasized in Iran. Lack of this issue is obvious through the recent interventions of the $9^{\text {th }}$ government known as Mehr House. In the settlements known as Mehr House that cannot be called neighborhood, there is no center of neighborhood. They are merely a shelter against bad climate. However, the articles which have studied the subject matter of sustainable communities (neighborhoods) are represented as follows:

- In his article titled as" making capacity for community development for reaching innovative and qualitative improvement in management and urban development relying on developing capacity for sustainable development", Pirbabaei (2004) shows that all social, economic, political, and physical activities in community level are called as development invention and they should be performed by complete participation of the local communities.

- The conference on community development (2004) was held in March. In the conference, valuable articles related to community development, community management, and role of people's participation in planning and management were presented. In the conference, different opinions were considered and community-based planning approach was known as the most functional approach of urbanism and urban planning.

- In his M.A. thesis titled as " feasibility of community development capacities for reaching sustainable urban development; case study: Kalkatehchi neighborhood located in Tabriz", Vahdani (2005) represents indices of the sustainable city and studies of potentially physical and human capacities in neighborhoods of Tabriz at a general level and the studied neighborhood at a smaller level in order to show that the plans for development of urban areas especially at local level have not considered the local abilities. Moreover, the residents' participation has not been considered, therefore, the plans have ignored the residents' needs. As a result, the plans and programs are not usable, the general budgets are wasted, and all has led to people's dissatisfaction with the development process at the community level. What should really be emphasized is the recognition of potentially local capacities in order to improve economic application at the level of urban communities.

- In his M.A. thesis titled as "community development planning with emphasis on economic capital, case study: Kooye Tolab located in Mashhad", Mousavi (2006) studies the relation between peoples' attitude toward physical environment of the community and the amount of economic capital and he declares that the decrease of population and area leads to the increase of economic capital.

- Mousa Kazemi and Shakouei assess the economic sustainability of Qom development and the results of the research show that regarding the applied indices of the research, there is some inconsistency in the indices of human and economic development of regions of Qom.

- Mohammad Rahim Rahnama et al. worked on a research study titled as qualitative improvement of modern urban communities by applying new urbanism (case study: Azad Shahr region located in Mashhad). They concluded that the deficiencies in the intellectual foundation of the mentioned region especially considering the merely physical perspective led to the formation of urban area with low life quality.

- Azizi (2006) studied "stability of residential neighborhood called Narmak". The research results show that the mentioned neighborhood could be considered as a sustainable and dynamic community. However, the bearing capacity of the community is saturated and paying attention to the bearing capacity could only be a guarantee 
for its sustainability.

\section{Research finding related to urban neighborhood development in Kowsar neighborhood}

\subsection{Research criteria and indices}

In order to analyze regeneration levels of Kowsar neighborhood, different methods and indices could be applied. Therefore, the considered index in this research has been studied in four aspects of sustainable development.

\subsubsection{Social criteria and indicators in Kowsar neighborhood}

The purpose of sustainability refers to the humans' survival which has ecological, economic, and social aspects (Sarafi, 2001, p. 15).sustainable urban life is the result of sustainable communities. In its broadest aspect, human's basic needs and humans' life quality improvement refers to social realm. At the lowest level of the spatial organization of cities, social indicators have represented better images for assessing sustainability of cities development, and sustainable development has a tendency to its social aspect and the principles related to it. In fact, what matters is the social sustainable development. The main issues related to the social aspect of sustainable development includes reduction of social tensions, organizing method in association with social conditions, equality with the disabled; religious, racial, and ethnic groups, and human rights equality, education, environmental awareness, health, and proper shelter for all, role of family and communities, and promotion of social values (Zangi abadi, 2005, p:40). Social indicators are declared as general indicators or total indicators which calculate per capita, densities, percentage, and ratios for the whole population and another indicator that shows the same quantities for men and women to determine the relative difference. Number of people, number of households and its aspects, and educational level based on gender in determined age groups are the social indicators applied in this research. The mentioned indicators are combined with health, cultural, and economic indicators to form physical-social and economic-social indicators (table 1).

Table 1: criteria and indicators for social stability and instability

\begin{tabular}{|c|l|c|c|c|l|}
\hline Row & Variables & Index & Stable & unstable & Explanations \\
\hline 1 & Number of households & Percent & $\sqrt{ }$ & & Indicates general growth rate \\
\hline 2 & Number of literate men & Percent & $\sqrt{ }$ & & Indicates general level of education \\
\hline 3 & Number of illiterate men & Percent & $\sqrt{ }$ & & Indicates general level of education \\
\hline 4 & Educating population & Percent & $\sqrt{ }$ & & Indicates general level of education \\
\hline 5 & $10-14$ year old population & Percent & & $\sqrt{ }$ & Indicates high rate of fertility and the need for control of population \\
\hline 6 & 65 and over 65 year old population & Percent & & $\sqrt{ }$ & Indicates the aging process of population \\
\hline 7 & Illiteracy rate & Percent & & $\sqrt{ }$ & Indicated low general level of public culture \\
\hline 8 & Aspect of family & Percent & & $\sqrt{ }$ & Indicates lack of social welfare and high level of fertility \\
\hline
\end{tabular}

\subsubsection{Economic criteria and indices in Kowsar neighborhood}

Regarding sustainable urban economy, the citizens should have enough employment and income opportunities so that they could provide new opportunities in accordance with the need increase (Sarafi, 2001, p. 13). Both social sustainability and environmental sustainability need a system of economic activities that should be compatible with the ecological and social networks of life on which our health, welfare and life quality depends.

In order to achieve human development and humans' desired ability a kind of economic activities is needed so that the current generation and the future generations could be sustainable socially and environmentally. Therefore, any discussion related to sustainable social communities should include a discussion related to its economic system. In fact, it is one of the important criteria for assessing economic poverty and urban poverty and it is also in relation with other aspects of urban poverty. Regarding social and population attitude toward economic aspect and urban communities' level, it is possible to provide area for each family, activity rate, women's activity rate, men's activity rate, dependency, and unemployment rate via census data. Moreover, area of commercial use at the level of urban community could be studied. If the economic index indicates quality and population welfare, environmental condition will not have a good condition assuming that undesirable economic conditions or economic poverty will be developed in the society. 
Table 2: criteria and indices of economic stability and instability

\begin{tabular}{|c|l|c|c|c|l|}
\hline Row & Variables & Index & Stable & unstable & Explanations \\
\hline 1 & Activity rate & Percent & $\sqrt{ }$ & & Indicates percentage of the employed in economic sector \\
\hline 2 & Area of commercial use & Percent & $\sqrt{ }$ & & Indicates economic importance of the region \\
\hline 3 & Women activity rate & Percent & $\sqrt{ }$ & & Indicates active population of actual women \\
\hline 4 & Men activity rate & Percent & $\sqrt{ }$ & & Indicates active population of actual men \\
\hline 5 & Surface area per household & Square meter & $\sqrt{ }$ & & Indicates economic situation \\
\hline 6 & Dependency ratio & Percent & & $\sqrt{ }$ & Indicates active people as the under control supervisors \\
\hline 7 & Unemployment rate & Percent & & $\sqrt{ }$ & Indicated percentage of unemployment in society \\
\hline
\end{tabular}

\subsubsection{Institutional and physical criteria and indices:}

It is necessary to make institutional structure for the urban governance in order to reach sustainability in all mentioned aspects. In other words, the power resulted from the citizens' will is needed to act considering sustainability, policies, and leading and observation. How the urban governance is performed is very important because it should make a balance among different aspects of urban sustainability. Therefore, the solutions are needed to address the conflicts among different goals of the city residents and also different goals of urban entrepreneurs for reaching sustainability (Sarafi, 2001, p. 25).

In the Iranian society of Iran, institutional sustainability depends on the property and well performing of the rules and plans provided by the high class urban organizations and in association with the urban organizations and municipality. Therefore, giving authority to the institutions which are formed based on the need and opinion of people of the city and suburbs indicate more sustainability. The society's responsibility and people's participation in making local institutions depends on gaining their trust. Financially and organizationally, after the approval of authority, providing; allocating; and equal distributing of local and national incomes will support the local plans performance. The citizens' tax paying depends on their trusting local consumption. Finally, equal distribution of services and facilities guarantees people's fair and desired access to their basic needs as well as their mutual participation. Without equal distribution of the infrastructures in all communities, sustainability is not achieved (Mousa Kazemi, 1997, p. 155).

The data that could be applied regarding this aspect of assessing sustainability refers to the information related to different applications related to basic and general needs and services, and number of public and private service centers. Allocating applications and providing facilities indicate institutional sustainability with regard to the principle of equality in development.

Table 3: criteria and indices for the institutional-physical sustainability

\begin{tabular}{|c|l|c|c|c|l|}
\hline Row & Variables & Index & Sustainable & unsustainable & Explanations \\
\hline 1 & Educational applicable area & Percent & $\sqrt{ }$ & & Chart of institutional-educational per capita \\
\hline 2 & Health applicable area & Percent & & $\sqrt{ }$ & Chart of institutional-health per capita \\
\hline 3 & Service applicable area & Percent & $\sqrt{ }$ & & Chart of institutional-service per capita \\
\hline 4 & Cultural and religious applicable area & Percent & & $\sqrt{ }$ & Chart of institutional-cultural per capita \\
\hline 5 & Sport applicable area & Percent & & $\sqrt{ }$ & Chart of institutional-leisure per capita \\
\hline 6 & Police and official area & Percent & $\sqrt{ }$ & & Chart of institutional-security per capita \\
\hline
\end{tabular}

\subsubsection{Environmental criteria and indices:}

The most important sustainability challenge refers to the decrease of natural resources and polluting the environment and also the irreversible harmful effects on the global ecosystem. It should be emphasized that protecting the environment along with reaching social-economic development are simultaneously possible. Moreover, the one-dimensional sustainability related to the environment is not achievable and if reached, it would be anti-social and inhuman. 
Table 4: Criteria and indices for environmental sustainability and unsustainability

\begin{tabular}{|c|l|c|c|c|l|}
\hline Row & Variable & Sustainable & Unsustainable & Index & Explanation \\
\hline$X_{1}$ & $\begin{array}{l}\text { Number of residential units over } 5 \\
\text { years old }\end{array}$ & $\sqrt{ }$ & & Percent & Level of security at living place \\
\hline$X_{2}$ & Green space applicable area & $\sqrt{ }$ & & Percent & Indicator of healthy environment of the neighborhood \\
\hline$X_{3}$ & Number of trash tanks & $\sqrt{ }$ & & Percent & \\
\hline$X_{4}$ & $\begin{array}{l}\text { Number of residential units over } \\
20 \text { years old }\end{array}$ & & $\sqrt{ }$ & Percent & Indicator of insecurity at the living place \\
\hline$X_{5}$ & Residential applicable area & & $\sqrt{ }$ & Percent & $\begin{array}{l}\text { Indicator of regional development and environmental } \\
\text { destruction }\end{array}$ \\
\hline$X_{6}$ & Industrial and workshop area & & $\sqrt{ }$ & Percent & Indicator of social-environmental pollution \\
\hline$X_{7}$ & Proper sewage disposal system & & $\sqrt{ }$ & $\begin{array}{c}\text { Square } \\
\text { meter }\end{array}$ & $\begin{array}{l}\text { Indicator of density of residential unit and lack of } \\
\text { proper drainage systems }\end{array}$ \\
\hline
\end{tabular}

\subsubsection{Determining the correlation and severity of indices regarding the development of Kowsar neighborhood}

With regard to the importance level of each of the critical criteria related to the development of the neighborhoods, it is possible to enter them into SPSS and also to assess the relation of each of the indices with neighborhood development considering Spearman's correlation coefficient and Pearson's level of significance. The following table indicates the neighborhood development in association with the level of development regarding "social, economic, institutionalphysical, and environmental" indices.

Table 5: level of relation between the indices and development of Kowsar neighborhood

\begin{tabular}{|l|c|}
\hline Indices & The percentage of effect of indices in community development \\
\hline social criteria and indicators in Kowsar neighborhood & $31 \%$ \\
\hline economic criteria and indices in Kowsar neighborhood & $24 \%$ \\
\hline physical-institutional criteria and indices in Kowsar neighborhood & $27 \%$ \\
\hline environmental criteria and indices in Kowsar neighborhood & $17 \%$ \\
\hline total & $100 \%$ \\
\hline
\end{tabular}

Table 6: assessment of amount of relation of indices with level of development of Kowsar neighborhood

\begin{tabular}{|c|c|c|c|c|c|}
\hline Dependent variable $X$ & Pearson's correlation & \multicolumn{4}{|c|}{ Independent variable: indices of Kowsar neighborhood development y1 } \\
\hline \multirow{3}{*}{$\begin{array}{c}\text { Level of developmet in Kowsar } \\
\text { neighborhood }\end{array}$} & Level of significance & Social & Economic & Institutional-physical & environmental \\
\hline & \multirow{2}{*}{ Severity of correlation } & 0.05 & 0.09 & 0.12 & 0.11 \\
\hline & & 0.47 & 0.32 & 0.26 & 0.25 \\
\hline
\end{tabular}

\section{Analysis}

Table 6 indicates Pearson's correlation coefficient on useful indices for development of Kowsar neighborhood. Respectively, the severity and direction of the relation between independent variables y1 ( social, economic, institutional and physical, and environmental indices) and the dependent variable $\mathrm{x}$ (Kowsar neighborhood development) equals 0.05 for the social index, 0.09 for the economic index, 0.12 for the institutional index, and 0.11 for the environmental index. All the indices have a positive relationship with the level of Kowsar neighborhood development. The maximum relationship between the mentioned indices and Kowsar neighborhood development is related to the social index (indicator) and it equals 0.47 . It could be mentioned as the first important index for reaching development. The minimum relationship regarding severity of correlation is related to the environmental index. It equals 0.25 , moreover, the economic index and the institutional-physical index have the second and the third ranks.

\section{Conclusion}

Rapid growth of population and its concentration in cities especially in metropolises lead to the emergence of social, 
economic, and environmental problems. Tehran as one of the metropolises out of 124 metropolises of the world that confronts many problems and it is far from the urban sustainability. Therefore, today sustainable development for Tehran has turned into a necessity. In the current urban society, the lower level of society" urban communities" or urban neighborhoods have a determining role in reaching sustainable urban development. With the purpose of improving neighborhood development and regenerating them at the level of cities, the neighborhoods could be considered regarding four studied social, economic, environmental, and institutional-physical indices. In this way, it is possible to take advantage of short term and long term programs to solve the problems related to each of the mentioned indices so that the neighborhood development could be enhanced and their regeneration at the level of city could be done.

In order to reach the purpose regarding sustainable development and systematic development in city, the first step to take is to recognize weaknesses and strengths, needs, and the shortages felt in the urban communities. According to the developmental research method and by using the four indices in different aspects of sustainable development, it is needed to lead Kowsar neighborhood to a desired social, economic, and environmental condition.

General problems and suggestions of the neighborhoods

Here, the problems of Kowsar neighborhood located in region 12 of Tehran have been mentioned:

- Performing decentralization policies and coordinating the local organizations regarding urban management in order to reach equality of the sustainability of neighborhoods and also considering sustainable neighborhoods for reaching sustainability in the unsustainable neighborhoods.

- Relative overcome of spaces and cross-regional applications and relative shortage of cross-regional applications

- Workshop and service units development

- The increasing trend of residential part of the region considering the activities development especially crossregional activities with regard to its being close to Tehran Bazaar.

- Lack of appropriate facilities and parking and the pedestrians' presence

- Being located in the traffic path and driving designs.

- High volume of pollutants as a result of concentration of official buildings, trash, and heavy traffics.

\section{General problems and suggestions}

1. Since the research follows sustainable development perspective, the development sustainability of Kowsar neighborhood has been studied based on its aspects. Therefore, many of the problems related to the studied neighborhood are mentioned as follows:

a. Social aspect: high population of the elderly, low level of people's participation, illiteracy, and high number of families.

b. Economic aspect: high rate of unemployment, high dependency ratio, and low level of household infrastructure.

c. Institutional-physical aspect: low level of per capita health, recreation, and green space.

d. Environmental aspect: presence of productive and industrial workshops in the Kowsar district, lack of water drainage in alley, and high density of buildings regarding the width of alley and the available services.

Therefore, the following suggestions are presented as follows:

- Development and enhancement of applications and performances in community-scale and control of the way of distributing applications.

- Leading small capitals to the small scaled productive activities which are compatible with the available applications of the community.

- Taking advantage of homogeneous activities and performances in accordance with the residential context and improving life quality.

- Making public and private parking and determining necessity of making and improving the pedestrians' accessibility via emphasizing the priority of the pedestrians' movement.

- Applying control policies and smoothing traffic flow

- Changing unused lands of the area into green and tree-planted spaces and control of height of constructions and also avoiding making obstacles to the air flow

- Investigating social status of the community considering the addicts and intruders

- Enhancing sense of participation and regeneration of civil participation for enhancing sense of belonging to the 
neighborhood

- Increasing service spaces and welfare facilities regarding the neighborhood needs

- Paying attention to the neighborhood environment for having a clean environment and being far from pollution with the participation of the residents.

\section{References}

Papoliyazdi, Mohammad Hosein, Sanajerdi, Hosein, "theories of city and subburbs", $1^{\text {st }}$ edit., Tehran, Samt pub.

Pirbabaei, Mohammad Taghi, (2004), "making capacity for community development", abstract of articles related to community development conference, sustainable development perspective", Tehran, $1^{\text {st }}$ edit., Tehran municipality

Hajpour, Khalil, (2004), "Community-based planning an efficient approach to make urban management", abstract of articles, articles of community development conference, sustainable development perspective of Tehran", 1'st edit., Tehran, Tehran municipality

Dickens, Peter, (2008), "Urban sociology", tran. Hosein, Behravan, 1st edit., Mashhad, Astan-e-Qods-e-Razavi pub.

Rosek, Joseph, Warren, Roland, (1990), "an introduction into sociology", 3rd edit. Tehran, Ahmadi pub.

Shokuei, Hosein, (2007)," social geography of city (social ecology of city)", 2nd edit., Tehran, Jahad-e-Daneshgahi pub.

Fukuyama, Francis, (2010), "the end of discipline (social capital and its maintenance)", trans. Gholamabas Tavasoli, Tehran, Jahan Afrooz pub.

Madanipour, Ali, (2004), "is it possible to make urban management and development based on communities", abstract of articles related to community development conference, sustainable development perspective", Tehran, $1^{\text {st }}$ edit., Tehran municipality

Mousavi, Seyed Yaghub, (2010), " a study on urban policies and new-community social development of Tehran", a sociological experience, abstract of articles related to community development conference, sustainable development perspective", Tehran, $1^{\text {st }}$ edit., Tehran municipality

Houdseni, Hanieh, (2005), " sustainable community development (theoretical concepts and historical origin)", urbanism M.A. seminar, Tarbiat-Modares university, Art faculty

Alvani, Seyed Mahdi, Seyed Taghavi, Mir Ali, (2002), "Social capital: concepts and theories", Management studies magazine, no. 33 